
specific method for quantification of CTC

SUBJECT AREAS:

BIOMARKER RESEARCH

METASTASES

CERVICAL CANCER

Received

19 September 2013

Accepted

20 January 2014

Published

5 February 2014

Correspondence and requests for materials should be addressed to

N.H. (norman.

haefner@med.uni-

jena.de) \section{in patients with cervical carcinoma}

Claudia Pfitzner, Isabel Schröder, Cornelia Scheungraber, Askin Dogan, Ingo Bernhard Runnebaum, Matthias Dürst \& Norman Häfner

Department for Gynaecology and Obstetrics, Jena University Hospital, Friedrich Schiller University, Germany.

The detection of circulating tumour cells (CTC) in cancer patients may be useful for therapy monitoring and prediction of relapse. A sensitive assay based on HPV-oncogene transcripts which are highly specific for cervical cancer cells was established. The Digital-Direct-RT-PCR (DD-RT-PCR) combines

Ficoll-separation, ThinPrep-fixation and one-step RT-PCR in a low-throughput digital-PCR format enabling the direct analysis and detection of individual CTC without RNA isolation. Experimental samples demonstrated a sensitivity of one HPV-positive cell in 500,000 HPV-negative cells. Spike-in experiments with down to $5 \mathrm{HPV}$-positive cells per millilitre EDTA-blood resulted in concordant positive results by PCR and immunocytochemistry. Blood samples from 3 of $10 \mathrm{CxCa}$ patients each contained a single

HPV-oncogene transcript expressing CTC among 5 to $15^{*} 10^{5}$ MNBC. Only 1 of 7 patients with local but 2 of 3 women with systemic disease had CTC. This highly sensitive DD-RT-PCR for the detection of CTC may also be applied to other tumour entities which express tumour-specific transcripts. Abbreviations: CTC circulating tumour cells, $\mathrm{CxCa}$ - cervical cancer, DD-RT-PCR - Digital-Direct Reverse Transcriptase PCR, HPV - Human Papilloma Virus, MNBC - mononuclear blood cells, ICC - immunocytochemistry.

ensitive and specific markers for blood-based analyses are still needed to improve primary diagnosis, risk stratification and surveillance of cancer patients ${ }^{1,2}$. Several classes of markers such as circulating DNA, miRNA or proteins are currently being evaluated ${ }^{3}$. However, the use of these markers for predicting the development or presence of distant metastases has not been validated in clinical studies. By contrast, the presence of CTCs at primary surgery and the dynamic change of CTCs during treatment correlate with response and progression-free survival ${ }^{4-6}$. Caused by the extreme under representation of CTCs among white and red blood cells (1 CTC in $>10^{6}$ white blood cells) the detection of CTCs is preceded by enrichment procedures. Different methods based on physical or biological properties were established for the depletion of blood cells or selective enrichment of $\mathrm{CTCs}^{5}$. The most frequently used techniques include erythrocyte lysis, density gradient centrifugation, immunomagnetic separation and size filtration methods. Importantly specific enrichment procedures need to be highly efficient and compatible with downstream methods for CTC detection. In principle, all properties of tumour cells if not present in blood cells could be used to detect CTCs. Available methods for detection include immunocytochemistry, reverse-transcription PCR and functional assays like EPISPOT or CAM all of which have their own advantages and limitations $s^{3}$. Reverse-transcription PCR (RT-PCR) enables the highly sensitive detection of specific transcripts characteristic for tumour cells ${ }^{7}$. A limitation of the current approaches using RT-PCR is the use of extracted RNA from the mononuclear cell fraction of the blood. On this basis the number of CTC can only be estimated because the expression level of the marker genes may vary among the CTC population. Moreover, although frequently used, epithelial cell-specific transcripts need to be interpreted with caution. Both the presence of non-tumour epithelial cells within the bloodstream and the possible illegitimate transcription of such genes in non-epithelial cells can contribute to false-positive results ${ }^{8,9}$. True tumour-specific transcripts are described for some tumour entities i.e. prostate and ovarian cancer but their use is limited to patients with tumours expressing these unique fusion transcripts ${ }^{10,11}$. Virus induced cancers i.e. cervical cancer $(\mathrm{CxCa})$ express viral oncogene transcripts specific for infected cells $s^{12,13}$. Cervical cancer is one of the most common cancers in women worldwide ${ }^{14}$. Over $99 \%$ of all $\mathrm{CxCa}$ are high-risk HPV-positive ${ }^{15}$. The oncogenic properties of these HPV are mediated by the viral oncogenes E6 and E7 which induce degradation and inactivation of the tumour suppressor proteins p53 and $\mathrm{pRb}$, respectively ${ }^{16,17}$. The tumour phenotype is strictly dependent on the sustained expression of E6 and E $7^{18}$. Inhibition of viral oncogene expression leads to the restoration of $\mathrm{p} 53$ and $\mathrm{pRb}$ function and induces apoptosis in 


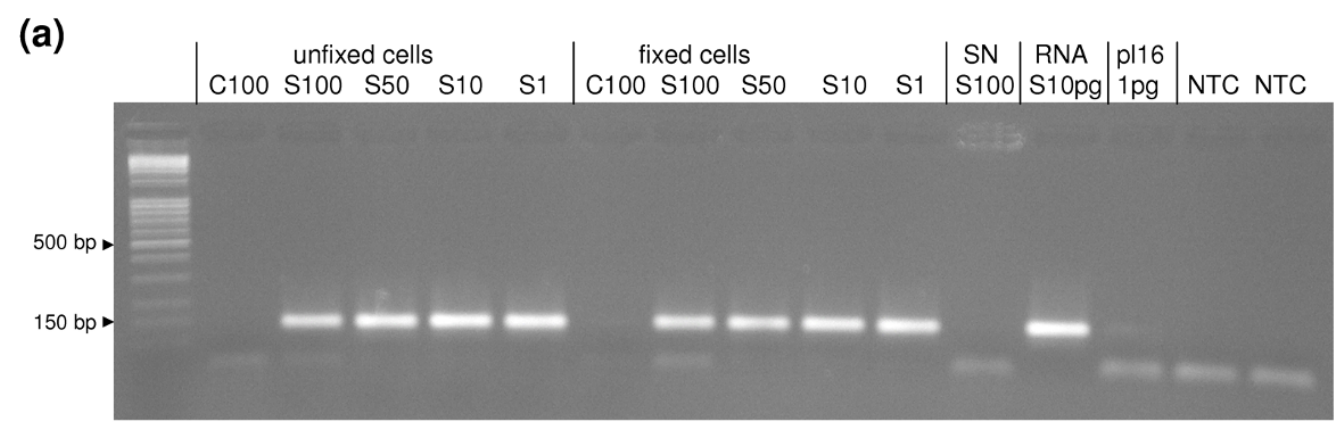

(b)

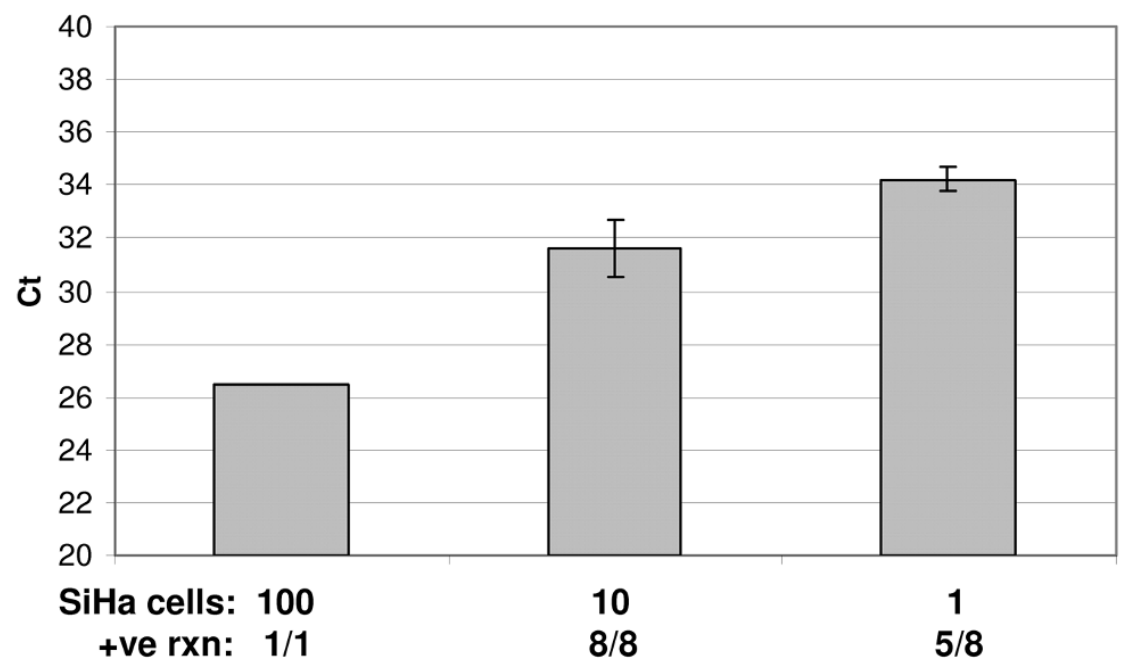

Figure 1 Characterisation of one-step RT-PCR for HPV16. (a) Gel electrophoresis of PCR products from following samples: (i) 1 to 100 unfixed or fixed $\mathrm{SiHa}$ (S) or $100 \mathrm{C} 33 \mathrm{~A}$ cells, (ii) the supernatant (SN) of 100 fixed SiHa cells, (iii) $10 \mathrm{pg}$ SiHa RNA and (iv) 1 pg of HPV16 plasmid. Samples with $\geq 1$ SiHa cell or containing SiHa RNA showed the expected PCR product (143 bp). Non-template-controls (NTC), HPV16 DNA and cell supernatant samples were not detected. (b) Different amounts of SiHa cells were analysed in a background of $200 \mathrm{C} 33 \mathrm{~A}$ cells. Increasing $\mathrm{C}_{\mathrm{T}}$-values correspond to the decreasing number of SiHa cells which could be reproducibly detected using the described assay (mean $\mathrm{C}_{\mathrm{T}}$-values of positive reactions \pm standard deviation).

CxCa cells ${ }^{19}$. Thus viral oncogene transcripts are ideal markers for the detection of tumour cells in cancer patients. Especially E6/E7 transcripts are superior to epithelial cell specific cytokeratin 19 transcripts for detection of disseminated tumour cells in lymph nodes of cervical cancer patients $^{20}$. Nevertheless E6/E7 expression levels are highly variable within $\mathrm{CxCa}$ cells impeding a simple correlation between transcript levels and the number of tumour cells ${ }^{21}$.

Therefore human papilloma virus (HPV) induced cervical cancer was used as a model system to establish a method for detection and quantification of CTCs by digital RT-PCR. Digital PCR (dPCR), first described in the Nineties, allows to quantitate the total number of initial targets present in a sample using limiting dilution, PCR and Poisson statistics ${ }^{22,23}$. Today, droplet- or array-based dPCR, each comprising a single nucleic acid target, enable thousands of reactions to be performed simultaneously. However, this droplet technology is not yet available for the enumeration of intact target cells. We hypothesize, that in analogy to the classical digital PCR for extracted nucleic acids, the low-throughput digital PCR approach ( $<100 \mathrm{rxn}$.) can also be used to detect and quantify rare CTC by a direct "on-cell" RT-PCR analysing several aliquots of isolated mononuclear blood cells (MNBCs). A quantification of CTCs within a small number of reactions is enabled by the extremely low number of CTCs if a high background of non-target cells is tolerated.

\section{Results}

Aim of this study was to establish a non-labour-intensive method for the detection and enumeration of rare circulating tumour cells in patients with cervical cancer. This was accomplished by a combination of (i) cell fixation, (ii) one-step RT-PCR and semi-nested qPCR and (iii) the use of a digital PCR approach. The strategy behind this combination is to enable the detection of single tumour cells, without the need for RNA extraction in a high background of mononuclear blood cells and their enumeration by splitting the whole sample (i.e. Ficoll-separated cells from $1 \mathrm{ml}$ blood) into several PCR reactions. The number of present tumour cells (in $1 \mathrm{ml}$ blood) should correspond to the number of positive reactions if $\leq 10 \%$ of aliquots are positive (see method section).

Establishment and validation of the digital PCR assay. Human papilloma virus oncogene transcripts are the target of the established assay. We used exon boundary spanning reverse primer to specifically detect the main transcript E6*I of HPV 16 or HPV $18^{21,24}$. Thus only viable HPV-positive cells but not cellular debris or HPV DNA will be detected by the RT-PCR. In first experiments one-step RT-PCR reactions were used. To minimize cell adhesion to plastic utensils a background of HPV-negative C33A cells (100200 cells/reaction) was included in samples with cells. Positive results showing the detection of specific transcripts using fixed intact cells for direct RT-PCR analysis were already published for a microfluidic helical tube reactor ${ }^{25}$. Figure 1 confirms these data and shows a specific detection of both one cell-equivalent SiHa-RNA and single unfixed and fixed SiHa cells. Importantly, negative controls comprising the cell suspension supernatant from 100 fixed $\mathrm{SiHa}$ cells and 1 pg HPV16 plasmid DNA ( $10^{6}$ molecules) did not show a specific amplification product. All further experiments used fixed 
(a)

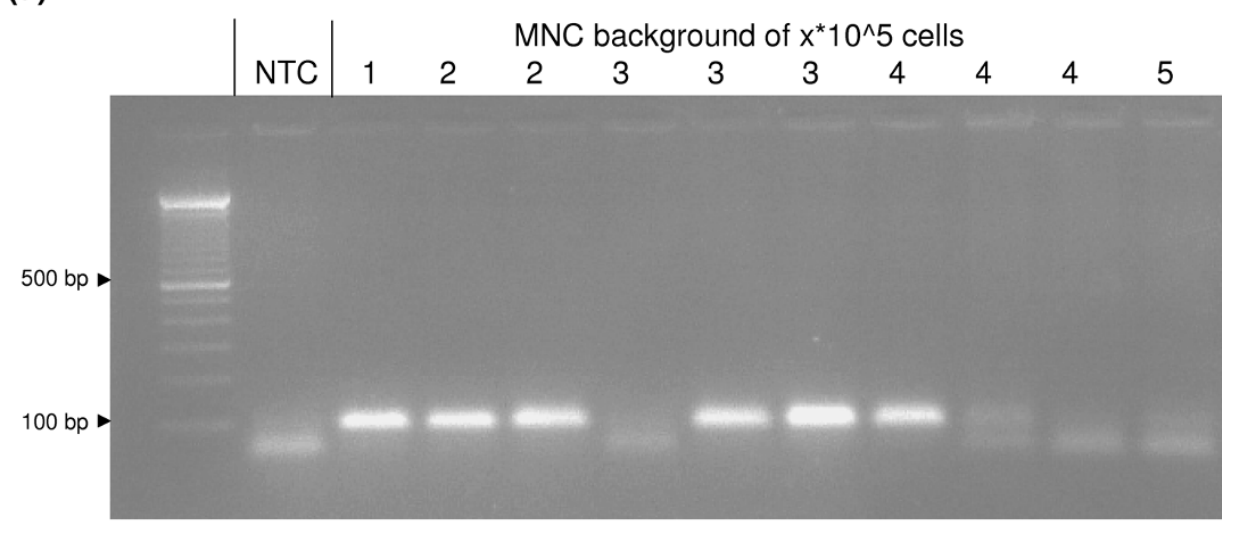

(b)

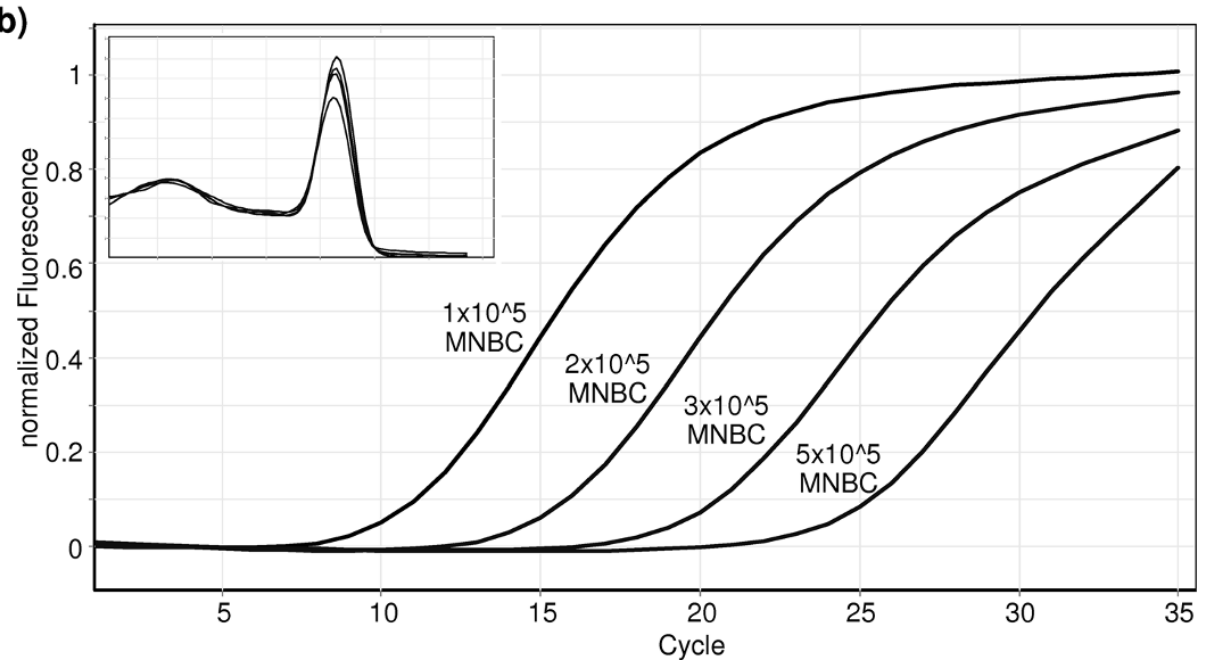

Figure $2 \mid$ Effects of varying numbers of isolated MNBCs. (a) Single SiHa cells were spiked into $1 \times 10^{5}$ up to $5 \times 10^{5}$ MNBCs and were subjected to the DD-RT-PCR assay. Samples with increasing numbers of up to $3 \times 10^{5}$ MNBCs could be reproducibly detected. (b) Comparable results were obtained for HPV18 assays using HeLa cells (2 cells per reaction). Higher numbers of MNBCs inhibit the assay leading to a shift of real-time amplification curves (for data see Suppl. Table S1). Melting curve analyses verified the correct amplification product (inset).

cells only, because unfixed cells showed a high rate of positive supernatants causing cross-contaminations (data not shown). ThinPrep PreservCyt solution was used because this fixative allowed both direct PCR and immunocytochemistry. This solution is commercially available and widely applied for Pap testing of cervical scrapes. Furthermore cell fixation protects cells from cell lysis after re-suspension in $0.1 \%$ Tween-20. Re-suspension in a diluted detergent is required to avoid cell adhesion to the plastic surface of pipet tips and reaction tubes. Diluted Tween-20 is compatible with direct RT-PCR and no cell damage was observed in immunocytochemistry (data not shown). Real-time PCR experiments revealed the expected cell-number-dependent differences in $\mathrm{C}_{\mathrm{T}}$-values, a $100 \%$ detection rate for 10 cells and $62.5 \%$ rate for 1 cell (Figure $1 \mathrm{~B}$ ). The detection rate for 1 cell is equal to the theoretical probability of analysing $>1$ cell assuming a Poisson distribution $(\mathrm{P}=63.21 \%)$. Thus the assay can detect single $\mathrm{SiHa}$ cells within the stochastical constraint. Moreover $\mathrm{SiHa}$ cells express a relative low amount of E6*I transcripts (1800 plasmid-copy equivalents in $10 \mathrm{ng}$ RNA) resembling the lowest decile of a $\mathrm{CxCa}$ patient cohort ${ }^{22}$. Thus $\mathrm{SiHa}$ cells represent an ideal model system and the established assay should exhibit an equal sensitivity in the majority of $\mathrm{CxCa}$ patients.

Analyses of experimental blood samples. All steps for the isolation of mononuclear blood cells (MNBC) should be compatible with downstream PCR assays. Ficoll separation and erythrocyte lysis were compared for enrichment of MNBCs and PCR inhibition was observed in samples obtained by the lysis method (data not shown). Thus, Ficoll separation was used for all experiments with blood samples. To enable the analysis of clinical samples the method must tolerate a high number of MNBC without losing the sensitivity for single target cells. Therefore, SiHa (HPV 16) and HeLa (HPV 18) cells were first analysed within a high background of MNBCs. A background of $>1000$ intact cells per reaction causes an increased SybrGreen fluorescence signal independent from the generation of PCR products thus interfering with real-time PCR detection but not the general amplification itself (data not shown). As a consequence the strategy was adapted to this requirement for clinical samples and a semi-nested PCR was used. The first PCR, directly coupled to the reverse transcription step (one-step RTPCR), amplifies the target sequence and an aliquot of this amplicon (with greatly reduced background cell number after centrifugation) is detected and quantified by the semi-nested qPCR.

Using this approach different amounts of $\mathrm{SiHa} / \mathrm{HeLa}$ cells were analysed after adding known numbers of MNBCs directly to the reaction (Figure 2). For both HPV types 1-2 target cells in up to 500,000 MNBCs were detected albeit an increase of inhibitory effects from MNBCs with increasing cell numbers was observed for both RNA- and cell samples (Figure 2 and Supplementary Tables S1, S2). Moreover, added cell numbers of $>300,000 \mathrm{MNBC}$ reduced the reproducibility/sensitivity of the assays (Figure 2B, Suppl. Tables 


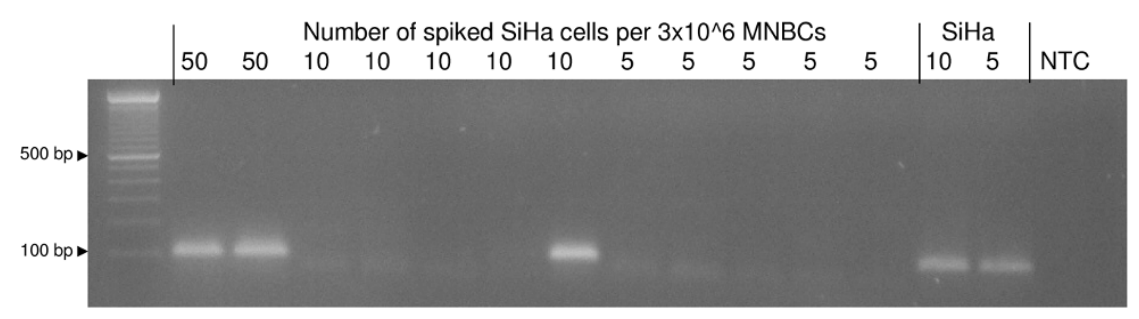

Figure 3 Analyses of artificial samples confirm the high sensitivity and the absence of cross-contaminations during the complete workflow. Three aliquots of $1 \mathrm{ml}$ blood $\left(3 \times 10^{6} \mathrm{MNBCs} / \mathrm{ml}\right)$ were spiked with different numbers of SiHa cells $(50,10$ or 5 cells $)$ resulting in $1,0.33$ or 0.16 target cells for each reaction with $1 \times 10^{5} \mathrm{MNBCs}$, respectively. These theoretical frequencies are reflected by the true frequencies of positive reactions for the three samples of $1(2 / 2), 0.2(1 / 5)$ and $0(0 / 5)$, respectively. ${ }^{\wedge}$.

S1, S2). Thus a limit of 200,000 MNBCs per reaction was set for clinical samples. Importantly, no positive reaction using varying amounts of MNBCs without spiked tumour cells was observed (Suppl. Tables S1, S2).

Samples consisting of freshly drawn blood from healthy donors were spiked with varying amounts of $\mathrm{SiHa} / \mathrm{HeLa}$ cells and analysed as described in the method section to validate the complete workflow. Independent experiments $(n=5)$ revealed a highly sensitive and reproducible detection of single $\mathrm{SiHa}$ or HeLa cells (Figure 3, Table 1). The number of PCR reactions required to detect the spiked cells was dependent on the number of MNBCs per ml blood. The first experiment used a blood sample with $3 \times 10^{6} \mathrm{MNBC}$ per $\mathrm{ml}$ blood. By spiking this sample with $50 \mathrm{SiHa}$ cells, each of the aliquots with 100000 MNBCs should include 1-2 SiHa cells. These were reproducibly detected (Figure 3 ). The same blood sample spiked with 10 or $5 \mathrm{SiHa}$ cells should include one $\mathrm{SiHa}$ cell in $1 / 3$ or $1 / 6$ of the aliquots, respectively. This theoretical rate of positivity was equalled in our experiments by detecting $\mathrm{SiHa}$ cells in $1 / 5$ and $0 / 5$ reactions, respectively (Figure 3$)$. Additional experiments $(n=4)$ used blood samples with $<2 \times 10^{6}$ MNBCs per $\mathrm{ml}$ thus enabling the analysis of one $\mathrm{ml}$ within 10 PCR reactions (Table 1). If all reactions reflecting $1 \mathrm{ml}$ blood were performed 14 of 17 expected $\mathrm{SiHa}$ cells could be identified by this PCR approach altogether in the different experiments (Table 1). To confirm these results aliquots of the isolated MNBCs were spotted onto slides and analysed by immunocytochemistry. Fifteen of 17 expected cells were identified by microscopic scanning confirming the PCR results (Table 1). Altogether these data provide proof for the detection and enumeration of rare tumour cells within a high background of MNBCs. Neither a loss of cells during the MNBC enrichment nor an increased rate of positive reactions that would point to possible cross contaminations was observed (Figure 3).

Quantification of CTCs in CxCa patients. After successful validation of this method blood samples from 10 patients with HPV 16 or HPV 18 positive cervical cancer (Table 2) were analysed. MNBCs of at least $2 \mathrm{ml}$ blood were isolated and aliquots representing $1 \mathrm{ml}$ of blood were subjected to DD-RT-PCR. Positive results were validated using samples from the second millilitre. Circulating tumour cells were detected in 3 of 10 patients and could be confirmed by repeating the analysis in all 3 cases. The number of CTCs varied between 1 in

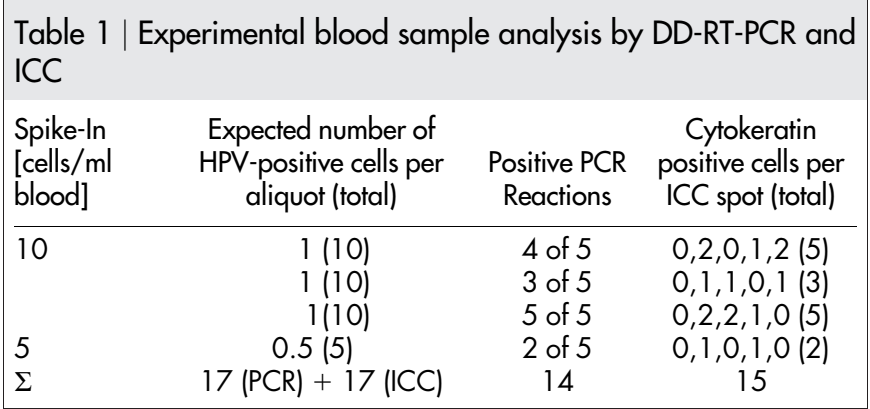

540,000 and 1 in 1,750,000 MNBCs. The CTC frequency in patient 10 (1 CTC in 540,000 MNBCs) is likely to be an underestimation because more than $10 \%$ of aliquots were positive (see methods section). Unfortunately, the experiments could not be repeated because this patient died shortly after the first analysis (Table 2). Importantly, the highest proportion of CTC-positive patients was identified within the group of patients with systemic disease (distant metastases; patients 7, 8 and 10; Table 2). Whereas only 1 of 7 patients (pat. 1) with local disease exhibited CTCs, 2 of 3 women with metastases were identified as being positive (pat. 7 and 10). Despite a good correlation between PCR and ICC results in experimental blood samples (Table 1) ICC analyses revealed no CTC in clinical samples (Table 2).

\section{Discussion}

Circulating tumour cells in peripheral blood are of prognostic relevance ${ }^{4}$. Most studies were done for patients with breast cancer. Indeed, alterations in the number of CTC over time were shown to be informative for treatment success and prognosis ${ }^{6}$. Available methods for the detection of CTCs are often time-consuming and require expensive equipment (i.e. CellSearch Veridex) or do not allow a direct quantitation of CTCs (RNA-extraction-based methods). Nevertheless, all methods rely on one or a combination of tumour cell specific markers. For virus-associated cancers i.e. cervical cancer viral transcripts are highly specific markers ${ }^{20}$. Furthermore, fusion transcripts present in different tumour entities or transcripts containing specific mutations could be established as tumour-specific markers. Such transcripts are superior to other markers that are tissue- rather than tumour-specific and highly susceptible to illegitimate transcription ${ }^{9}$. Additionally non-tumour cells from the tissue in which the tumour had its origin may lead to false positive results ${ }^{8,26}$. Such false positives can also be caused by the induction of epithelial tissue-specific genes in haematopoietic cells by cytokines $^{27}$.

We are not aware of any published data using a digital PCR approach for the enumeration of circulating tumour cells. The data available from (commercial) high-throughput digital PCR systems (droplet-, array-based) are based on extracted nucleic acids (i.e. cellfree plasma DNA) thus precluding the enumeration of CTCs. Moreover, most commercial systems for digital PCR are underpowered for the single cell analysis among $>10^{6} \mathrm{MNBCs}$. In a previous publication we had shown proof-of-principle for the analysis of intact cells in a low-throughput microfluidic system ${ }^{26}$. That protocol may in part be adapted to high-throughput droplet-based digital PCR systems for the direct use of cells.

Given a true tumour-cell specificity of the molecular marker used, we hypothesized that a method combining (i) Ficoll-separation of MNBCs, (ii) cell fixation and (iii) one-step-RT-PCR with a digital PCR approach should enable the detection and enumeration of CTCs. These three steps are necessary to (i) exclude the presence of erythrocytes, (ii) avoid cross contaminations by cell lysis and (iii) enable enumeration of cells. The established assay for the model 


\begin{tabular}{|c|c|c|c|c|c|c|c|c|c|c|c|}
\hline patient & $\begin{array}{l}\text { TNM primary } \\
\text { tumor }\end{array}$ & G & $\mathrm{R}$ & L & V & $\begin{array}{c}\text { clinical status } \\
\text { blood withdrawal }\end{array}$ & $\begin{array}{l}\text { follow up status, } \\
\text { time to event }\end{array}$ & HPV & +ve PCR & CTC count (PCR) & + ve ICC \\
\hline 2 & $\mathrm{pT} 2 \mathrm{~b}, \mathrm{pN} 1, \mathrm{MO}$ & 2 & 1 & 0 & 0 & 2. local relapse & local relapse, 24 month & 18 & $0 / 10$ & $0 / 1,270,000$ & $0 / 6$ \\
\hline 3 & pT4, pN1, MO & 2 & 0 & 1 & $x$ & NOD & NOD, 23 month & 16 & $0 / 11$ & $0 / 1,590,000$ & $0 / 6$ \\
\hline 4 & pT4, pN1, MO & 3 & 1 & 0 & 0 & 1. local relapse & DOD, 5 month & 18 & $0 / 20$ & $0 / 1,700,000$ & $0 / 6$ \\
\hline 7 & pT2, pNo, M1 & 2 & 1 & 0 & 0 & 1. local relapse & distant relapse, 11 month & 16 & $2 / 35$ & $1 / 1,750,000$ & $0 / 6$ \\
\hline 8 & pT3b, pN1, M1 & 2 & 1 & 0 & $x$ & local and distant progression & DOD, 5 month & 16 & $0 / 20$ & $0 / 4,100,000$ & $0 / 6$ \\
\hline 9 & pT2b, pNO, MO & 3 & 0 & 0 & 0 & primary surgery & local relapse, 12 month & 16 & $0 / 20$ & $0 / 3,400,000$ & $0 / 6$ \\
\hline 10 & pT2b, pN1, MO & 3 & 0 & 1 & 1 & local and distant relapse & DOD, 1 day & 16 & $13 / 38$ & $1 / 540,000$ & $\begin{array}{c}\text { not } \\
\text { evaluable }\end{array}$ \\
\hline
\end{tabular}

system of cervical cancer detected single target cells within a high background of non-target cells in experimental blood samples (Figure 3, Table 1). The DD-RT-PCR enables a practicable digital PCR approach to quantify low numbers of CTCs within MNBCs by analysing several pools of isolated cells (each pool $<200,000$ MNBCs). The volume of blood to be analysed is only restricted by the number of PCR reactions per sample. The method can be adapted for samples with greatly increased frequencies of CTC by reducing the number of MNBCs per reaction. Therefore it may be necessary to conserve diluted aliquots by freezing if a high number of CTCs is expected.

Clinical samples of cervical cancer patients revealed the presence of CTCs in line with published data. Due to the small number of cases we cannot draw clinically relevant conclusions but the concordance with already published data confirms the generation of accurate data by the DD-RT-PCR. Circulating tumour cells were detected in $2 / 3$ (66.6\%) patients with systemic disease (Table 2). Analyses of isolated RNA from MNBCs resulted in a rate of $92.3 \%$ of FIGO IVb patients which were HPV 16 mRNA positive ${ }^{28}$. This higher rate is probably due to the larger blood volume $(10 \mathrm{ml})$ used for RNA isolation and the inherent difference to our study: detection of RNA molecules vs. enumeration of CTCs. In a follow up study the authors observed a significant association of HPV mRNA positivity and the development of distant metastases in patients with advanced $\mathrm{CxCa}$ (univariate analysis $)^{29}$. Whereas 8 of 18 patients positive for HPV mRNA developed metastases only 1 of 17 patients without HPV mRNA suffered from distant relapse ${ }^{29}$. A significant correlation between the presence of HPV-DNA positive cells within blood or bone marrow and both recurrence and survival was also described by Scheungraber and colleagues ${ }^{30}$. In contrast to the $66.6 \%$ detection rate in patients with systemic disease we detected CTCs in peripheral blood from only 1 of 7 patients with local disease (14.2\%). This patient did not develop distant disease within a current follow up of 30 months. Thus the presented and published data suggest that most patients with metastasizing tumours are CTC positive whereas
CTC negative patients have local disease and a lower risk of developing metastases. Nevertheless some patients with CTCs do not develop distant disease confirming the requirement for additional specific properties of CTCs to seed metastases. The low number of CTCs in cervical cancer patients is also reported from Weismann and colleagues who detected HPV transcripts in blood from 3/13 patients $^{31}$.

The DD-RT-PCR was validated with immunocytochemical staining for cytokeratins confirming PCR results for experimental blood samples with spiked cells from SiHa or HeLa (1/100,000 cells). However, CTCs in patient blood samples were not detected by ICC likely caused by the lower number of CTCs in clinical samples $(\leq 1 /$ 540,000 cells). Thus ICC analyses exhibit a lower sensitivity for the detection of rare CTCs in clinical samples. To further examine the presence of CTCs in cervical cancer patients, additional experiments using single-cell RT-PCRs on EpCAM-positive cells were performed (data not shown). After erythrocyte lysis, enrichment of EpCAMpositive cells and staining for EpCAM and CD45, single non-haematopoietic cells were picked for RT-PCR. In only one of seven patients a single HPV-positive cell among 50 analysed cells was detected. This confirms the DD-RT-PCR results pointing to a low number of CTCs in cervical cancer patients and exemplifies the insufficient specificity of epithelial antigens as CTC marker. Nevertheless, the presence of a mesenchymal phenotype caused by Epithelial-Mesenchymal-Transition (EMT) of CTCs leading to false negative ICC or EpCAM-enrichment results cannot be excluded. However, an EMT process may not inhibit HPV oncogene expression because loss of E6/E7 leads to apoptosis and reduced cell survival $^{18,19}$.

Altogether, using the highly sensitive DD-RT-PCR a combination of Ficoll-separation, cell fixation and one-step RT-PCR low numbers of HPV16/18-E6 expressing cells could be quantified in a high background of HPV-negative cells. This practicable approach may also be employed for different tumour entities if highly tumour-specific transcripts are given.

\begin{tabular}{|c|c|c|c|c|c|c|c|}
\hline \multirow[t]{2}{*}{16} & RT-PCR & $\begin{array}{l}\text { HPV16 F } \\
\text { HPV16 R E6*1 }\end{array}$ & NC001526 & $\begin{array}{l}F \\
R\end{array}$ & $\begin{array}{l}\text { AATGTTTCAGGACCCACAGG } \\
\text { CTTTTGACAGTTAATACACCTCACG }\end{array}$ & 58 & 143 \\
\hline & semi-nested & $\begin{array}{l}\text { HPV16 F int } \\
\text { HPV16 R E6*1 }\end{array}$ & & $\begin{array}{l}F \\
R\end{array}$ & $\begin{array}{l}\text { CACAGAGCTGCAAACAACTATACA } \\
\text { CTTTTGACAGTTAATACACCTCACG }\end{array}$ & 58 & 95 \\
\hline \multirow[t]{2}{*}{18} & & $\begin{array}{l}\text { HPV18 F } \\
\text { HPV18 R E6*I }\end{array}$ & AY262282 & $\begin{array}{l}\mathrm{F} \\
\mathrm{R}\end{array}$ & $\begin{array}{l}\text { GATCCAACACGGCGAC } \\
\text { ACCGCAGGCACCTCT }\end{array}$ & 57 & 125 \\
\hline & & HPV18 R int & & $\mathrm{R}$ & ССTCTGTAAGTTCCAATACTGTC & & \\
\hline
\end{tabular}

*splice-specific, joining nt226-409 (HPV16) and n+233-416 (HPV18). 
done according to manufacturer's instructions (Dako) and cells were counterstained

\section{Methods}

Patients and cell cultures. All patients were treated for primary or relapsed cervical cancer at the Department of Gynaecology at the Jena University Hospital and gave their informed consent to be included in this study. The ethics committee of Jena University Hospital approved the study and consent forms (\#2655-09/09). The conducted study strictly adhered to the approved protocols and the guidelines of the ethics committee. Blood samples were taken prior to clinical procedures using EDTA monovettes and stored at $4^{\circ} \mathrm{C}$ until isolation of cells within 2 hours. Tumour tissue or cervical scrapes of all patients were used to isolate DNA and to determine the prevalent HPV type. HPV typing was done by established methods ${ }^{32,33}$. Only HPV type 16 and 18 positive patients were included in this study.

Cells of HPV 16 and HPV 18 positive and HPV negative cell lines (SiHa, HeLa and $\mathrm{C} 33 \mathrm{~A}$, respectively) were used to establish and validate the complete workflow. Cells were cultured in standard medium (RPMI or DMEM) with supplementation of $10 \%$ fetal calf serum and $1 \%$ penicillin/streptomycin in a humidified incubator $\left(5 \% \mathrm{CO}_{2}\right.$, $\left.37^{\circ} \mathrm{C}\right)$.

\section{Isolation and fixation of mononuclear blood cells and tumour cells. The} isolation of cells was done by Ficoll-separation. Two millilitre of EDTA-blood were transferred into a LeukoSep tube (Greiner, Germany) prefilled with Ficoll-Paque Plus (GE Healthcare, Germany) and centrifuged at $838 \mathrm{~g}$ for 15 minutes at $20^{\circ} \mathrm{C}$. Most of the plasma volume was removed and the complete Ficoll-phase above the separation disk containing mononuclear cells was transferred into a new collection tube containing $1 \mathrm{ml}$ cold phosphate-buffered saline (PBS). To this new tube a further $1 \mathrm{ml}$ PBS, which was used to wash the upper part of the LeukoSep tube to recover all residual cells, was added. Isolated cells were pelleted by a centrifugation step $\left(10 \mathrm{~min}, 140 \mathrm{~g}, 4^{\circ} \mathrm{C}\right)$ with deactivated brakes. The cell pellet was fixed in $2 \mathrm{ml}$ ThinPrep solution (Cytyc Corporation, USA) for 1 hour on ice. After centrifugation $\left(5 \mathrm{~min}, 389 \mathrm{~g}, 4^{\circ} \mathrm{C}\right)$ the cell pellet was washed with $0.5 \mathrm{ml} 0.1 \%$ Tween- 20 , transferred into $1.5 \mathrm{ml}$ tubes, centrifuged again and resuspended in $340 \mu \mathrm{l} 0.1 \%$ Tween-20 solution. This solution corresponds to 20 samples (á $17 \mu \mathrm{l}$ ) each resembling $100 \mu \mathrm{l}$ of blood volume. Aliquots $(17 \mu \mathrm{l})$ were used for immunocytochemistry, analysed by RT-PCR or stored at $-80^{\circ} \mathrm{C}$. Artificial samples (blood of healthy volunteers spiked with different numbers of SiHa or HeLa cells) were treated equally to clinical samples. One aliquot was always used to count the number of cells. If more than 200,000 cells were present within one aliquot, aliquots for PCR or freezing were appropriately diluted.

One-step RT-PCR and semi-nested qPCR. Aliquots of isolated and fixed mononuclear blood cells were directly analysed by a semi-nested RT-PCR approach. The first PCR included the reverse transcription step using genespecific priming (one-step RT-PCR). All primers used are listed in table 3 . The reaction $(25 \mu \mathrm{l})$ consisted of $1 \times$ reaction buffer and $0.5 \mu \mathrm{l}$ enzyme mix (Transcriptor one-step RT-PCR Kit, Roche, Germany), 10 pmol forward and reverse primer and $17 \mu \mathrm{l}$ cell suspension. The reaction steps were as follows: reverse transcription $30 \mathrm{~min} 50^{\circ} \mathrm{C}$; initial denaturation and hot-start activation $10 \min 95^{\circ} \mathrm{C} ; 20$ PCR cycles of $15 \sec 95^{\circ} \mathrm{C} ; 20 \sec 58^{\circ} \mathrm{C} ; 40 \sec 68^{\circ} \mathrm{C}$ and were done in a Mastercycler (Eppendorf, Germany). Afterwards reactions were centrifuged at $367 \mathrm{~g}$ for $4 \mathrm{~min}$ and $2 \mu \mathrm{l}$ of the supernatant were transferred to the second PCR. This semi-nested PCR was run as a real-time PCR using SybrGreen dye in a Rotorgene 5plexHRM (Qiagen, Germany). Reactions were performed in $25 \mu \mathrm{l}$ volume containing: dNTP $(240 \mu \mathrm{M}$ each $)$, forward and reverse primer (12.5 pmol each), DMSO (5\%), $\mathrm{MgCl}_{2}(1.75 \mathrm{mM})$, Tris- $\mathrm{HCl} \mathrm{pH8.3}(10 \mathrm{mM}), \mathrm{KCl}$ $(50 \mathrm{mM})$, gelatine $(0.001 \%)$, SybrGreen $(0.025 \times)$ and AmpliTaqGold $(1.25 \mathrm{U})$ (Applied Biosystems, Germany). The PCR steps were as follows: Initial denaturation and hot start activation at $95^{\circ} \mathrm{C}$ for 10 min followed by 40 cycles of denaturation phase at $95^{\circ} \mathrm{C}$ for $15 \mathrm{sec}$, primer annealing for $20 \mathrm{sec}$ at $58^{\circ} \mathrm{C}$ and elongation at $72^{\circ} \mathrm{C}$ for $40 \mathrm{sec}$. Subsequently the melting temperature of the PCR product was determined to ensure specificity.

Digital PCR. A low-throughput digital PCR approach was used by splitting cells from $1 \mathrm{ml}$ of blood into $\geq 10$ reactions with $\leq 200,000$ cells per aliquot. In order to quantify CTCs by this method a positive RT-PCR result needs to be based on a single CTC. If among the aliquots more than $10 \%$ of the reactions are positive the sample requires to be diluted. Otherwise, assuming a Poisson distribution, more than $5 \%$ of the positive PCRs would contain $>1$ CTC. The frequency of CTC within MNBCs is then calculated by dividing the number of CTCs (= positive PCR reactions) by the number of analysed MNBCs (number of PCR reactions * MNBCs per reaction).

Immunocytochemistry (ICC). Six aliquots of isolated cells were spotted onto slides and allowed to dry. The staining procedure was performed with the DAKO Envision Detection Kit (Dako, Germany). Although we included an incubation step with hydrogen peroxide $(0.6 \%)$ we observed the staining of single immune cells caused by endogen peroxidase catalysed dye conversion in validation experiments. To eliminate this unspecific staining we included a heat-induced epitope retrieval step in citrate buffer ( $\mathrm{pH}$ 6) presumably resulting in peroxidase inactivation (data not shown). After hydrogen peroxide treatment and blocking of unspecific binding sites with goat serum (Dako) primary pan-cytokeratin antibody (AE1/AE3, 1:500 dilution, Dako) was incubated overnight at $4^{\circ} \mathrm{C}$. Secondary antibody and substrate incubation were with haematoxylin. All staining experiments included negative controls (without primary antibody)

1. Diamandis, E. P. Cancer biomarkers: can we turn recent failures into success? J Natl Cancer Inst 102, 1462-7 (2010).

2. Negm, R. S., Verma, M. \& Srivastava, S. The promise of biomarkers in cancer screening and detection. Trends Mol Med 8, 288-93 (2002).

3. Alix-Panabieres, C., Schwarzenbach, H. \& Pantel, K. Circulating tumor cells and circulating tumor DNA. Annu Rev Med 63, 199-215 (2012).

4. Cristofanilli, M. et al. Circulating tumor cells: a novel prognostic factor for newly diagnosed metastatic breast cancer. J Clin Oncol 23, 1420-30 (2005).

5. Paterlini-Brechot, P. \& Benali, N. L. Circulating tumor cells (CTC) detection clinical impact and future directions. Cancer Lett 253, 180-204 (2007).

6. Pachmann, K. et al. Monitoring the response of circulating epithelial tumor cells to adjuvant chemotherapy in breast cancer allows detection of patients at risk of early relapse. J Clin Oncol 26, 1208-15 (2008).

7. Zieglschmid, V., Hollmann, C. \& Bocher, O. Detection of disseminated tumor cells in peripheral blood. Crit Rev Clin Lab Sci 42, 155-96 (2005).

8. Bustin, S. A., Siddiqi, S., Ahmed, S., Hands, R. \& Dorudi, S. Quantification of cytokeratin 20, carcinoembryonic antigen and guanylyl cyclase $\mathrm{C}$ mRNA levels in lymph nodes may not predict treatment failure in colorectal cancer patients. Int J Cancer 108, 412-7 (2004).

9. Chelly, J., Concordet, J. P., Kaplan, J. C. \& Kahn, A. Illegitimate transcription: transcription of any gene in any cell type. Proc Natl Acad Sci U S A 86, 2617-21 (1989).

10. Narod, S. A., Seth, A. \& Nam, R. Fusion in the ETS gene family and prostate cancer. Br J Cancer 99, 847-51 (2008).

11. Salzman, J. et al. ESRRA-C11orf20 is a recurrent gene fusion in serous ovarian carcinoma. PLoS Biol 9, e1001156 (2011).

12. Durst, M., Glitz, D., Schneider, A. \& zur Hausen, H. Human papillomavirus type 16 (HPV 16) gene expression and DNA replication in cervical neoplasia: analysis by in situ hybridization. Virology 189, 132-40 (1992).

13. Schwarz, E. et al. Structure and transcription of human papillomavirus sequences in cervical carcinoma cells. Nature 314, 111-4 (1985).

14. Parkin, D. M., Bray, F., Ferlay, J. \& Pisani, P. Global cancer statistics, 2002. CA Cancer J Clin 55, 74-108 (2005).

15. Walboomers, J. M. et al. Human papillomavirus is a necessary cause of invasive cervical cancer worldwide. J Pathol 189, 12-9 (1999).

16. Scheffner, M., Werness, B. A., Huibregtse, J. M., Levine, A. J. \& Howley, P. M. The E6 oncoprotein encoded by human papillomavirus types 16 and 18 promotes the degradation of p53. Cell 63, 1129-36 (1990).

17. Gonzalez, S. L., Stremlau, M., He, X., Basile, J. R. \& Munger, K. Degradation of the retinoblastoma tumor suppressor by the human papillomavirus type $16 \mathrm{E} 7$ oncoprotein is important for functional inactivation and is separable from proteasomal degradation of E7. J Virol 75, 7583-91 (2001).

18. von Knebel Doeberitz, M., Rittmuller, C., zur Hausen, H. \& Durst, M. Inhibition of tumorigenicity of cervical cancer cells in nude mice by HPV E6-E7 anti-sense RNA. Int J Cancer 51, 831-4 (1992).

19. Butz, K. et al. siRNA targeting of the viral E6 oncogene efficiently kills human papillomavirus-positive cancer cells. Oncogene 22, 5938-45 (2003).

20. Häfner, N. et al. HPV16-E6 mRNA is superior to cytokeratin 19 mRNA as a molecular marker for the detection of disseminated tumour cells in sentinel lymph nodes of patients with cervical cancer by quantitative reverse-transcription PCR. Int J Cancer 120, 1842-6 (2007).

21. Häfner, N. et al. Integration of the HPV16 genome does not invariably result in high levels of viral oncogene transcripts. Oncogene 27, 1610-7 (2008).

22. Vogelstein, B. \& Kinzler, K. W. Digital PCR. Proc Natl Acad Sci U S A 96, 9236-41 (1999).

23. Sykes, P. J. et al. Quantitation of targets for PCR by use of limiting dilution. Biotechniques 13, 444-9 (1992).

24. Sherman, L., Alloul, N., Golan, I., Durst, M. \& Baram, A. Expression and splicing patterns of human papillomavirus type-16 mRNAs in pre-cancerous lesions and carcinomas of the cervix, in human keratinocytes immortalized by HPV 16, and in cell lines established from cervical cancers. Int J Cancer 50, 356-64 (1992).

25. Hartung, R. et al. Application of an asymmetric helical tube reactor for fast identification of gene transcripts of pathogenic viruses by micro flow-through PCR. Biomed Microdevices 11, 685-92 (2009).

26. Bostick, P. J. et al. Limitations of specific reverse-transcriptase polymerase chain reaction markers in the detection of metastases in the lymph nodes and blood of breast cancer patients. J Clin Oncol 16, 2632-40 (1998).

27. Jung, R. et al. Specificity of reverse transcriptase polymerase chain reaction assays designed for the detection of circulating cancer cells is influenced by cytokines in vivo and in vitro. Br J Cancer 78, 1194-8 (1998)

28. Pao, C. C., Hor, J. J., Yang, F. P., Lin, C. Y. \& Tseng, C. J. Detection of human papillomavirus mRNA and cervical cancer cells in peripheral blood of cervical cancer patients with metastasis. J Clin Oncol 15, 1008-12 (1997).

29. Tseng, C. J. et al. Detection of human papillomavirus types 16 and $18 \mathrm{mRNA}$ in peripheral blood of advanced cervical cancer patients and its association with prognosis. J Clin Oncol 17, 1391-6 (1999). 
30. Scheungraber, C. et al. Detection of disseminated tumor cells in patients with cervical cancer. J Cancer Res Clin Oncol 128, 329-35 (2002).

31. Weismann, P. et al. The detection of circulating tumor cells expressing E6/E7 HRHPV oncogenes in peripheral blood in cervical cancer patients after radical hysterectomy. Neoplasma 56, 230-8 (2009).

32. Jacobs, M. V. et al. A general primer GP5+/GP6(+)-mediated PCR-enzyme immunoassay method for rapid detection of 14 high-risk and 6 low-risk human papillomavirus genotypes in cervical scrapings. J Clin Microbiol 35, 791-5 (1997).

33. Schmitz, M. et al. Quantitative multiplex PCR assay for the detection of the seven clinically most relevant high-risk HPV types. J Clin Virol 44, 302-7 (2009).

\section{Acknowledgments}

We thank Lars Jansen for preparing tissue sections used for HPV typing. This work was supported by a fellowship of the Interdisciplinary Centre for Clinical Research (IZKF) Jena to C.P.

\section{Author contributions}

C.P. and N.H. established the method; C.P. and I.S. analysed clinical samples; C.S., A.D. and I.B.R. organized sampling of clinical material and supported clinical data management; M.D. and N.H. developed the project idea, supervised the work and drafted the paper. All authors approved the final manuscript version.

\section{Additional information}

Supplementary information accompanies this paper at http://www.nature.com/ scientificreports

Competing financial interests: The authors declare no competing financial interests.

How to cite this article: Pfitzner, C. et al. Digital-Direct-RT-PCR: a sensitive and specific method for quantification of CTC in patients with cervical carcinoma. Sci. Rep. 4, 3970; DOI:10.1038/srep03970 (2014).

(c) (1) (2) (2) This work is licensed under a Creative Commons Attribution-

(c) ${ }_{\text {BY No }}$ sA NonCommercial-ShareAlike 3.0 Unported license. To view a copy of this license, visit http://creativecommons.org/licenses/by-nc-sa/3.0 